\section{Efficacy of photodynamic therapy in circumscribed choroidal haemangioma}

\begin{abstract}
Purpose To report efficacy of photodynamic therapy (PDT) in the treatment of three cases of juxtafoveal circumscribed choroidal haemangioma.

Methods Data on three patients (two primary, and one failed TTT) treated with verteporfin, $6 \mathrm{mg} / \mathrm{m}^{2}$ given as i.v. infusion over $10 \mathrm{~min}$. Diode laser $(690 \mathrm{~nm})$ with an intensity of $600 \mathrm{~mW} / \mathrm{cm}^{2}$ for $83 \mathrm{~s}\left(50 \mathrm{~mJ} / \mathrm{cm}^{2}\right)$ was applied $5 \mathrm{~min}$ after completion of infusion.

Overlapping multiple spots $(2500 \mu \mathrm{m})$ were applied to cover the entire surface of the tumour. The mean pretreatment tumour size was $7 \mathrm{~mm}$ (base) $\times 2.2$ (thickness) $\mathrm{mm}$. Periodic follow-up with ophthalmoscopy, ultrasonography, and angiographic studies was performed.

Results All three cases showed complete regression of the tumour with resolution of subretinal fluid, flattening of tumour, and absence of choroidal vasculature on ICG. The visual acuity either improved or remained stable in all three cases. The overlying retinal vessels remained unaffected. There were no ocular or systemic complications.

Conclusions PDT is an effective treatment for management of juxtafoveal circumscribed choroidal haemangioma.

Eye (2004) 18, 139-142. doi:10.1038/

sj.eye. 6700597
\end{abstract}

Keywords: photodynamic therapy; choroidal neoplasms; haemangioma

\section{Introduction}

Choroidal haemangioma is an uncommon benign vascular tumour of the choroid, which can be either circumscribed or diffuse. The
M Gupta, AD Singh, PA Rundle and IG Rennie

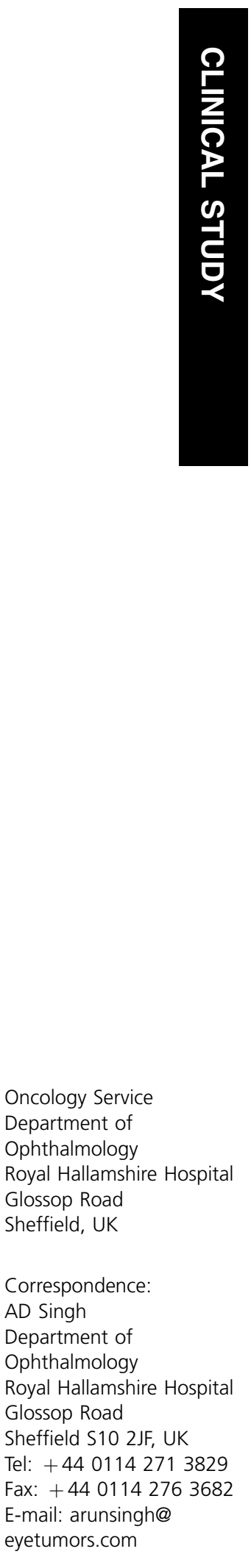

circumscribed form of choroidal haemangioma is usually a solitary tumour without any other ocular or systemic association. The diffuse form however is usually part of Sturge-Weber syndrome. The choroidal haemangiomas are usually diagnosed between the second and fourth decade of life when they cause visual disturbance because of exudative retinal detachment. ${ }^{1}$

As choroidal haemangioma is a benign tumour, the aim of the treatment is to limit or reduce the visual compromise caused by the subretinal fluid or by foveal distortion owing to underlying tumour. Since choroidal haemangioma is usually in the posterior pole, it is important to ensure the least amount of damage to the overlying retina to conserve visual acuity. Various modalities have been tried for the treatment of circumscribed choroidal haemangioma, including argon laser photocoagulation, ${ }^{2}$ cryotherapy, ${ }^{3}$ external beam radiotherapy, ${ }^{4}$ proton beam radiotherapy, ${ }^{5}$ episcleral plaque radiotherapy, ${ }^{6}$ and transpupillary thermotherapy (TTT). ${ }^{7}$ All these techniques have been reported with varying degrees of success in stabilizing or improving visual acuity, but the major limitation with all these treatment modalities has been the risk of damage to the overlying retina.

Photodynamic therapy (PDT) is a new treatment option for treating circumscribed choroidal haemangiomas. With the use of photosensitizer, which is injected intravenously and pools within the vascular channels of the choroidal haemangioma, and irradiation at a specific wavelength, site-specific cell destruction can be achieved with sparing of the overlying retina and retinal vasculature. ${ }^{8}$ Conceptually, PDT would seem to appear as an ideal method for the treatment of circumscribed choriodal haemangiomas. In fact, few case
Received: 27 January 2003 Accepted in revised form: 21 March 2003 
reports have been published where excellent tumour regression with preservation of overlying retina has been observed following treatment with PDT. In this report, we present our experience with three cases of symptomatic juxtafoveal circumscribed choroidal haemangioma that were treated successfully with PDT.

\section{Materials and methods}

All three patients were referred to the Ocular Oncology service of a tertiary hospital where they received their treatment. A uniform standard regime was followed in all cases. The patients were given $6 \mathrm{mg} / \mathrm{m}^{2}$ of verteporfin as an intravenous infusion over $10 \mathrm{~min}$. PDT was performed with a diode laser $(690 \mathrm{~nm})$ with an intensity of $600 \mathrm{~mW} / \mathrm{cm}^{2}$ for an exposure of $83 \mathrm{~s}\left(50 \mathrm{~mJ} / \mathrm{cm}^{2}\right) 5 \mathrm{~min}$ after completion of infusion. Volk PDT lens was used in all cases. Overlapping multiple spots were applied to cover the entire surface of the tumour.

\section{Case 1}

A 49-year-old female was seen in the clinic complaining of decreased vision in her left eye for 9 months. There was no other significant past ocular or medical history. On examination, the visual acuity was $6 / 9$ in the right eye and 6/36 in the left eye. Anterior segment examination of both eyes and fundus examination of the right eye were normal. In the left fundus, a raised amelanotic lesion juxtafoveal in location with minimal subretinal fluid was noted (Figure 1a). The tumour was $6 \mathrm{~mm}$ in basal diameter and $2.5 \mathrm{~mm}$ in thickness. Fluorescein angiography and indocyanine green angiography showed early hyperfluorescence and progressive leakage with washout phenomenon in late phases, highly suggestive of a circumscribed choroidal

Figure 1 (a) Fundus photograph of the left eye showing an amelanotic juxtafoveal circumscribed choroidal haemangioma. (b) Fluorescein angiogram (arterio-venous phase). Note circumscribed hyperfluorescence corresponding to the location of the choroidal haemangioma. (c) Indocyanine green angiogram showing hypervascularity and hyperfluorescence because of choroidal haemangioma. (d) B-scan ultrasonograph of a domeshaped choroidal lesion and high internal reflectivity (thickness $2.5 \mathrm{~mm}$ ). (e) Central visual field defects documented prior to photodynamic therapy. (f) Post-treatment fundus appearance showing regression of haemangioma. (g) Post-treatment fluorescein angiogram showing absence of pretreatment hyperfluorescence. (h) Post-treatment indocyanine green angiogram demonstrating that the choroidal haemangioma is replaced by an area of hypovascular choroid. (i) Post-treatment B-scan ultrasonograph showing complete flattening of the choroidal hemangioma. (j) Post-treatment central visual field. Note lack of progression of pretreatment field defects. haemangioma (Figure $1 \mathrm{~b}$ and $\mathrm{c}$ ). The patient was initially observed for 18 months over which she complained about fluctuating levels of vision in the left eye. As a result of increasing symptoms, she was treated with PDT with an application of five overlapping spots of $2500 \mu \mathrm{m}$ at the retinal level. Within 3 weeks, the haemangioma showed complete resolution with no evidence of
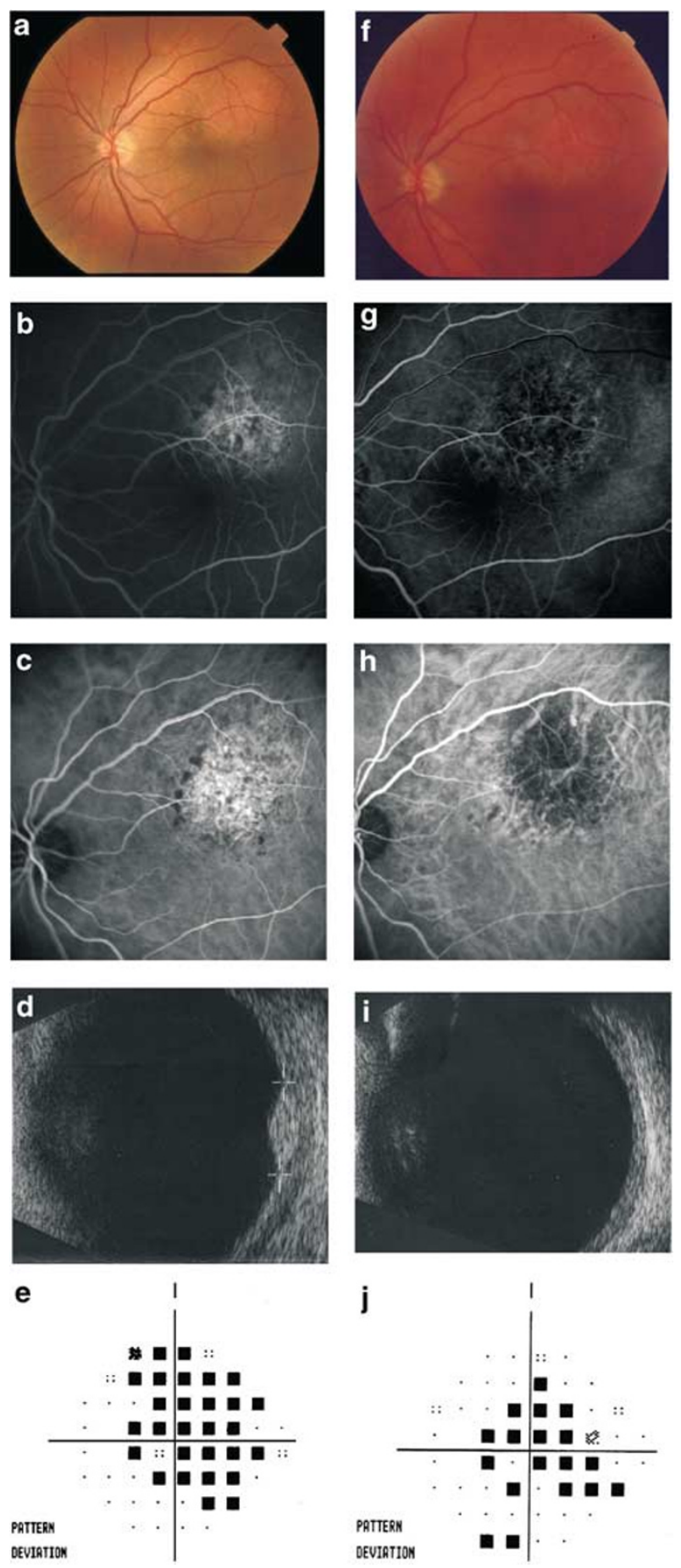
subretinal fluid (Figure 1f). On B-scan ultrasonography, it appeared flat (Figure 1d and i). The area of hyperflourescence noted on pretreatment angiograms was now replaced by an area of hypovascular choroid (Figure $1 \mathrm{~g}$ and $\mathrm{h}$ ). The overlying retina and retinal vessels were normal. The visual acuity improved to $6 / 12$ and there was slight improvement in the pretreatment field defects (Figure 1e and j).

\section{Case 2}

A 63-year-old male was noted by the optician to have a field defect and a retinal lesion in the right eye. The patient was asymptomatic and there was no significant medical history. On examination, the visual acuity was $6 / 6$ in the right eye and $6 / 5$ in the left eye. Fundus examination showed a raised amelanotic lesion along the inferotemporal vessels extending towards the fovea. Clinical examination and the ancillary imaging studies confirmed the diagnosis of circumscribed choroidal haemangioma. The tumour was $9.0 \mathrm{~mm}$ in basal diameter and $2.3 \mathrm{~mm}$ in thickness. The patient was observed for a year and when he became symptomatic, with the visual acuity dropping to $6 / 9$ owing to the subretinal fluid, the haemangioma was treated with PDT with partial regression. After 2 months, repeat PDT with seven spots (2500-5000 $\mu \mathrm{m}$ on the retina) was performed. Since then, there is stable and complete regression of the haemangioma with a visual acuity of $6 / 6$.

\section{Case 3}

A 46-year-old male was referred with a 3-month history of blurred vision in his right eye and a lesion along the superotemporal vessels. The diagnosis at referral was of amelanotic melanoma. On examination, the visual acuity was $6 / 9$ in the right eye and $6 / 5$ in the left eye. There was no significant past ocular or medical history. Anterior segment examination of both eyes and the fundus examination of the left eye were normal. Dilated fundus examination of the right eye showed an illdefined amelanotic lesion along the superotemporal arcade. It was $6.0 \mathrm{~mm}$ in basal diameter and $1.9 \mathrm{~mm}$ in thickness on B-scan ultrasonography. There was subretinal fluid in the macular area. Angiographic studies with fluorescein and indocyanine green corroborated the clinical diagnosis of solitary circumscribed choroidal haemangioma. As the patient was minimally symptomatic, it was elected to observe the patient. On periodic follow-up, the lesion remained stable until 3 years later when the vision dropped to $6 / 18$ with an increase in the size of the haemangioma. The patient was initially treated with indocyanine green augmented transpupillary thermotherapy to the extrafoveal portion of the haemangioma. With progressive worsening of the visual acuity to $6 / 24$, it was elected to treat the residual haemangioma with PDT. A spot size of 2500 was used on the retina and the patient had 10 overlapping spots to cover the whole extent of the tumour. On follow-up examination 6 weeks later, the visual acuity improved to $6 / 18$ and regression of the tumour was observed. The tumour appeared flat on Bscan ultrasonography and hypovascular on indocyanine green angiography. The patient is still under follow-up.

\section{Discussion}

Circumscribed choroidal haemangiomas are usually located in the posterior pole of the fundus close to the optic disc or fovea. ${ }^{1}$ Patients with choroidal

haemangioma usually present with visual symptoms of either reduced vision or metamorphopsia related to foveal distortion owing to underlying tumour or accumulation of serous subretinal fluid. The visual loss can be progressive and irreversible because of chronic oedema in the foveal region leading to photoreceptor loss. On the other hand, some cases are diagnosed on routine examination in asymptomatic patients.

The decision to treat choroidal haemangioma should be individualized based upon the extent of symptoms, visual loss, and potential for visual recovery. The aim of the treatment is to induce sufficient tumour atrophy with resolution of subretinal fluid and tumour-induced foveal distortion. As compared to previously reported methods of treatment such as argon laser photocoagulation, ${ }^{2}$ cryotherapy, ${ }^{3} \mathrm{TTT}^{7}$ and various forms of radiotherapy, ${ }^{4-6}$ PDT is superior as it offers a location-specific modality of treating choroidal haemangioma with a potential of sparing overlying retina and retinal vessels. Moreover, it is an outpatient procedure performed under topical anaesthesia and usually only one session of treatment is required..$^{9}$ The use of PDT for the treatment of choroidal tumours was piloted by Schmidt-Erfurth $e t a l^{12}$ and was found to cause complete and irreversible occlusion of the microvasculature in choroidal tumorus. Since then it has been used in the treatment of symptomatic juxtafoveal circumscribed haemangiomas with good results with a follow-up period of up to 1 year. ${ }^{11-13}$ In our three cases, tumour regression was excellent with sparing of overlying retina over a follow-up period of 4-6 months. The visual acuity in all our cases either remained stable or improved following PDT. One of our cases did not show adequate response after PDT and needed a second session of PDT following which there was complete resolution of the tumour with no side effects. This illustrates that in case of inadequate response or recurrence, repeat PDT can be performed safely in the 
Table 1 Summary of ophthalmoscopic features of three cases of choroidal haemangioma treated with photodynamic therapy

\begin{tabular}{|c|c|c|c|c|c|c|c|c|}
\hline \multirow[t]{2}{*}{ Case number } & \multicolumn{4}{|c|}{ Pretreatment } & \multicolumn{4}{|c|}{ Post-treatment } \\
\hline & $\begin{array}{l}\text { Base } \\
(\mathrm{mm})\end{array}$ & $\begin{array}{c}\text { Thickness } \\
(\mathrm{mm})\end{array}$ & $S R F$ & Vision & Base (mm) & $\begin{array}{l}\text { Thickness } \\
(\mathrm{mm})\end{array}$ & $S R F$ & Vision \\
\hline Case 1 & 6.0 & 2.5 & Present & $6 / 36$ & 6.0 & Atrophy & Absent & $6 / 12$ \\
\hline Case 2 & 9.0 & 2.3 & Present & $6 / 6$ & 9.0 & Atrophy & Absent & $6 / 6$ \\
\hline Case 3 & 6.0 & 1.9 & Present & $6 / 24$ & 6.0 & Atrophy & Absent & $6 / 18$ \\
\hline
\end{tabular}

setting of choroidal haemangioma as it is done in cases of subretinal neovascular membranes (Table 1).

The basis of PDT is to initiate photochemistry at the target sites. Following administration of verteporfin (a photosensitizer) intravenously, the tumour is irradiated at a specific wavelength $(690 \mathrm{~nm})$. Verteporfin selectively pools in choroidal haemangioma because of numerous vascular channels in the tumour and possibly by the uptake of the lining endothelial cells. ${ }^{14,15}$ The mechanism of cell destruction in cases of choroidal haemangioma is presumed to be because of a combination of direct cytotoxicity and vascular occlusion. $^{8}$

We have followed the standard PDT protocol used for treatment of subretinal neovascular membranes with excellent results in choroidal haemangiomas. Previously published reports and our own experience of three cases suggest that over the short term, PDT seems to be a safe and effective option for the treatment of juxtafoveal circumscribed choroidal haemangioma. PDT is contraindicated in patients with porphyria and liver dysfunction. In addition, precautions should be taken for $48 \mathrm{~h}$ following PDT against excessive sun exposure and bright lights used in surgical procedures. Long-term observations on treated patients are necessary to fully evaluate the efficacy of PDT.

\section{References}

1 Anand R, Augsburger JJ, Shields JA. Circumscribed choroidal hemangiomas. Arch Ophthalmol 1989; 107: 1338-1342.

2 Sanborn GE, Augsburger JJ, Shields JA. Treatment of circumscribed choroidal hemangiomas. Ophthalmology 1982; 89: 1374-1380.

3 Humphrey WT. Choroidal hemangioma response to cryotherapy. Ann Ophthalmol 1979; 11: 100-104.
4 Ritland JS, Eide N, Tasujo J. External beam irradiation therapy for choroidal hemangiomas. Visual and anatomical results after a dose of 20-25 Gy. Acta Ophthalmol Scand 2001; 79: 184-186.

5 Hannouche D, Frau E, Desjardins L, Cassoux N, Habrand JL, Offret H. Efficacy of proton therapy in circumscribed choroidal hemangiomas associated with serous retinal detachment. Ophthalmology 1997; 104: 1780-1784.

6 Kreusel KM, Bornfeld N, Lommatzsch A, Wessing A, Foerster MH. Ruthenium-106 brachytherapy for peripheral retinal capillary hemangioma. Ophthalmology 1998; 105: 1386-1392.

7 Kamal A, Watts AR, Rennie IG. Indocyanine green enhanced transpupillary thermotherapy of circumscribed choroidal hemangioma. Eye 2000; 14: 701-705.

8 Schmidt-Erfurth U, Hasan Tayyaba. Mechanism of action of photodynamic therapy with vertoporfin for the treatment of age-related macular degeneration. Surv Ophthalmol 2000; 45(3): 195-213.

9 Madreperla SA. Choroidal hemangioma treated with photodynamic therapy using verteporfin. Arch Ophthalmol 2000; 119: 1606-1610.

10 Schmidt-Erfurth U, Baumann W, Gragoudas E, Flotte TJ, Michaud NA, Birngruber R et al. Photodynamic therapy of experimental choroidal melanoma using lipoproteindelivered benzoporphyrin. Ophthalmology 1994; 101: 89-99.

11 Barbazetto I, Schmidt- Erfurth U. Photodynamic therapy of choroidal hemangioma: two case reports. Graefe's Arch Clin Exp Ophthalmol 2000; 238: 214-221.

12 Landau IME, Steen B, Seregard S. Photodynamic therapy for circumscribed choroidal hemangioma. Acta Ophthalmol Scand 2002; 80: 521-536.

13 Jurklies B, Anastassiou G, Ortmans S, Schuler A, Schilling $\mathrm{H}$, Schmidt-Erfurth $\mathrm{U}$ et al. Photodynamic therapy using verteporfin in circumscribed choroidal hemangioma. $\mathrm{Br} J$ Ophthalmol 2003; 87(1): 84-89.

14 Jamieson $\mathrm{CH}$, McDonald WN, Levy JG. Preferential uptake of benzoporphyrin derivative by leukemic versus normal cells. Leuk Res 1990; 14: 209-219.

15 Roberts WG, Hasan T. Role of neovasculature and vascular permeability on the tumor retention of photodynamic agents. Cancer Res 1992; 52: 924-930. 